\title{
Aqueous Long-Term Solubility of Titania \\ Nanoparticles and Titanium(IV) Hydrolysis in \\ a Sodium Chloride System Studied by \\ Adsorptive Stripping Voltammetry
}

Jochen Schmidt $^{1,2^{*}}$ and Wolfram Vogelsberger ${ }^{1}$

(1) Institute of Physical Chemistry, Chemistry and Earth Science Faculty, Friedrich-Schiller-University Jena, Helmholtzweg 4, D07743 Jena, Germany

(2) Institute of Particle Technology, University of ErlangenNuremberg, Cauerstraße 4, D-91058 Erlangen, Germany

Telephone: +49 (0) 91318529408

Fax: +49 (0) 91318529402

j.schmidt@lfg.uni-erlangen.de

The final publication is available at Springer via http://dx.doi.org/10.1007/s10953-009-9445-9 


\begin{abstract}
The solubility of industrially produced titanium dioxide nanoparticles has been studied in aqueous sodium chloride media in the $\mathrm{pH}$ range 1 to 13 at $25{ }^{\circ} \mathrm{C}$ by adsorptive stripping voltammetry (AdSV). Kinetic dissolution curves as well as long-term solubilities that provide an approximation of equilibrium solubility have been obtained. The titania nanoparticles used in the dissolution experiments have been characterized by nitrogen sorption measurements, XRD and colloid titration.. The equilibrium solubilities and titanium(IV) speciation in dependence on $\mathrm{pH}$ have been modelled by assuming mononuclear titanium hydroxo complexes $\left[\mathrm{Ti}(\mathrm{OH})_{n}{ }^{(4-\mathrm{n})+}(\mathrm{n}=2 \ldots 5)\right.$ to be the only titanium species present. The solubility product of titanium dioxide and equilibrium constants for titanium(IV) hydrolysis calculated from the AdSV solubility data are presented.
\end{abstract}

Keywords Titania; Nanoparticles; Dissolution; Titanium(IV) hydrolysis; Adsorptive stripping voltammetry of Ti(IV) 


\section{Introduction}

Titania is used in many applications in technology and everyday life because of its excellent dielectric and chemical properties [1-3]. With the increasing use and synthesis of nanomaterials there arise questions on the stability of nanostructures as well as the toxicity of nanoparticles [4-6] regarding dissolution phenomena, as ultrafine particles can easily be incorporated. Moreover in synthesis knowledge about solubility and aqueous chemistry is a crucial parameter to control particle size, particle shape and phase or aggregation behaviour [7-13]. It can be seen from these different points of view that reliable information about the dissolution kinetics as well as the equilibrium solubility of even sparingly soluble matter like titanium dioxide and particle size effects on solubility in general [14-16] has to be established.

In aqueous media $(\mathrm{pH}>1)$ at ambient temperature crystalline bulk titanium dioxide shows small equilibrium solubilities that only can be quantified by means of trace analysis. Perhaps it is due to this fact that there only exist few recent publications that deal with the experimental determination of the aqueous solubility of titania or hydrous titanium oxide under rather moderate dissolution conditions $[11,14,17,18]$. At geologically relevant conditions, i.e. at high pressure and high temperature, data on the solubility of titania are available (see e.g. refs. [19-21]).

Ziemniak et al. performed solubility measurements of rutile in the temperature range $17{ }^{\circ} \mathrm{C}$ to $288{ }^{\circ} \mathrm{C}$ in an autoclave flow system at alkaline $\mathrm{pH}$ in aqueous sodium phosphate media, sodium hydroxide and ammonia solutions [17]. They found nanomolal to micromolal titanium(IV) solubilities under these alkaline conditions and give in their article comprehensive thermochemical parameters for the $\mathrm{TiO}_{2}-\mathrm{H}_{2} \mathrm{O}$ system. The quantitative titanium determinations have been performed with AAS after preconcentration of the sample solutions.

More recent Knauss et al. studied the solubility of rutile over a broad $\mathrm{pH}$ range from $\mathrm{pH} 1$ to $\mathrm{pH} 13$ in buffer solutions at temperatures of 100 to $300{ }^{\circ} \mathrm{C}$ [18]. They found solubilities measured by ICP-MS of about $10^{-6.3} \mathrm{~mol} / \mathrm{kg}$ at $\mathrm{pH} 1(100$ $\left.{ }^{\circ} \mathrm{C}\right)$ and $10^{-7}$ molal at $\mathrm{pH} 2\left(100{ }^{\circ} \mathrm{C}\right)$. At $\mathrm{pH} 6.5$ and $8.5\left(100{ }^{\circ} \mathrm{C}\right)$ comparable molal solubilities of about $10^{-7.7} \mathrm{~mol} / \mathrm{kg}$ are reported. In accordance with the findings of Ziemniak et al. an increase in titanium(IV) solubility in the alkaline $\mathrm{pH}>11$ is observed, too. 
Sugimoto et al. [11] studied the solubility of a freshly prepared amorphous titanium oxide by the means of ICP-OES. While Knauss et al. found similar results like Ziemniak et al. for the titania equilibrium solubilities, Sugimoto et al. present solubilities of a freshly precipitated titanium oxide that shows several orders of magnitude higher solubilities than the crystalline polymorphs. The increased solubility of freshly precipitated or amorphous oxides or hydrous oxides of titanium is well-known. It is therefore inevitable to perform a thorough characterisation of the solid used in dissolution experiments.

Some results [22, 23] on the formation of aqueous hydroxo complexes of titanium(IV) are contradictory; the characteristics of the solid are often not well described and frequently amorphous samples or samples containing titanium hydrous oxide phase $[11,24]$ were studied.

Due to this rather fragmentary knowledge on the equilibrium solubility of crystalline titanium dioxide at ambient temperatures $\left(25^{\circ} \mathrm{C}\right)$-and especially on the solubility of titania nanoparticles- we decided to perform studies on the dissolution kinetics $[14,15]$, as well as on the long-term solubilities of industrially produced titanium dioxide nanostructured particles to be reported here. Moreover the solubility of a titanium hydrous oxide samples has been studied in the acidic $\mathrm{pH}$ range in order to demonstrate the effect of hydration / hydroxylation of the solid. The dissolution studies have been carried out in aqueous sodium chloride solutions of $\mathrm{pH} 1$ to 13 in a closed system. As the formation of titanium chloro complexes [25] and polynuclear titanium complexes [26, 27] under the experimental conditions can be neglected, the aqueous titanium(IV) speciation has been modelled with mononuclear titanium hydroxo complexes $\left[\mathrm{Ti}(\mathrm{OH})_{\mathrm{n}}\right]^{(4-\mathrm{n})+}(\mathrm{n}=$ 2 ... 5) and stepwise and cumulative hydrolysis constants have been derived. The solids have been characterized by XRD, nitrogen sorption measurements and colloid titration. The quantitative analysis of titanium(IV) trace amounts dissolved has been performed by adsorptive stripping voltammetry (AdSV) in the potassium chlorate - mandelic acid system [28].

\section{Experimental}

2.1 Setup of dissolution experiment and sampling 
All chemicals used, if not otherwise stated, were of special purity, i.e. for trace analysis or puriss. p. a. As far as possible glass equipment was omitted, instead lab equipment made of PP, PMP or PTFE was used. The dissolution experiments with industrially produced titanias P25 (Evonik Degussa), DT51D (Millenium Chemicals), G5 (Millenium Chemicals) and an uncalcined titanium hydrous oxide slurry TRONOX Hydrate Paste (Tronox) were performed in a closed system (50 $\mathrm{ml}$ to $500 \mathrm{ml}$ PP or PTFE bottles) at $(25+/-1){ }^{\circ} \mathrm{C}$. Details on these titanium oxides are given in the section "Results and Discussion". The bottles were stored on a shaker (Unimax 1010, Heidolph Instruments) at 150/min (switched on daily for at least 8 hours) in an incubation hood. A background electrolyte concentration of $0.1 \mathrm{M} \mathrm{NaCl}$ was applied, the $\mathrm{pH}$ value was adjusted by the addition of $0.1 \mathrm{M}$ to 1 $\mathrm{M} \mathrm{HCl}$ (dilution of $37 \% \mathrm{HCl}$ Fluka, TraceSelect) or $0.1 \mathrm{M} \mathrm{NaOH}$ or concentrated $\mathrm{NaOH}$ (Merck, p.a.). For pH measurements the pH meter 540 GLP (WTW) was used. The initial surface area to solvent volume ratio, i.e. the surface area according to the BET method of the sample under consideration exposed to the volume of the electrolyte solution, was $40 \mathrm{~m}^{2} / 100 \mathrm{~mL}$ in all experiments.

The dispersions were prepared by introducing the appropriate amount of the titania solid (dried at $110{ }^{\circ} \mathrm{C}$ ) into the electrolyte solution of the pre-adjusted $\mathrm{pH}$ and temperature while stirring at 400/min (magnetic stirring device). At once after addition of the solid the $\mathrm{pH}$ value was adjusted and the bottle was transferred into the incubation hood.

The following sampling procedure was applied: after dissolution times of at least 500 hours (for long-term solubility data) up to $10 \mathrm{~mL}$ of the dispersion were withdrawn. The solid residue was separated from the sample solution to be analysed by centrifugation (10 minutes at 4100/min with the device Z320 (Hermle)) and by filtration (cellulose acetate, $0.2 \mu \mathrm{m}$, Schleicher \& Schuell). No particles could be detected within the filtered solution as was confirmed by dynamic light scattering measurements (DLS). The filtered sample solutions with a $\mathrm{pH}$ smaller than or equal to $\mathrm{pH}=2$ were stored in PP-bottles without altering the $\mathrm{pH}$. The less acidic filtered sample solutions up to $\mathrm{pH} 7$ were adjusted to $\mathrm{pH} 2$ by addition of $\mathrm{HCl}$ for the storage to prevent the formation of polymeric species and precipitation. The samples of alkaline $\mathrm{pH}$ were stored at the solution $\mathrm{pH}$ value. The $\mathrm{pH}$ necessary for the AdSV determination ( $\mathrm{pH}$ 3.3) was adjusted in the 
presence of mandelic acid just before the measurement. If possible the AdSV titanium determinations were performed within one day after sampling.

\subsection{Adsorptive stripping voltammetry (AdSV)}

AdSV has been used as a preferred determination method. The results of the AdSV method are established by ICP-MS measurements [14]. The advantage of AdSV compared to ICP-MS is that particles possibly not removed by the filtration are detected as increased titanium content by ICP-MS. It has been proven experimentally that AdSV works well even in the presence of relatively large amounts of colloid particles [29]. The quantification of the titanium(IV) content in the solution, was performed by adsorptive stripping voltammetry $(\mathrm{AdSV})$ in the mandelic acid - $\mathrm{KClO}_{3}$ system, using a VA Computrace 757 device (Metrohm) in DP-Mode. The reduction of a titanium(IV) - mandelic acid complex is evaluated and the signal is enhanced by a catalytic current [28]. A hanging mercury drop electrode (HMDE) was used as the working electrode. The voltammetric parameters applied and the composition of the supporting electrolyte are summarized in Table 1 (a). The standard addition method (three additions, threefold replications) was used. If necessary the $\mathrm{pH}$ was adjusted to 3.0 - 3.3 by addition of $\mathrm{NH}_{3}$ or $\mathrm{HCl}$. The peak current, corrected for the baseline determined by a blank measurement, has been evaluated using VA Computrace 1.0 software. All reagents applied, were of the specification suprapure or puriss p.a., respectively, in order to minimize analytical blanks. The detection limit of the method applying the parameters summarized in Table 1 was found to be 0.026 ppb as calculated from calibration graphs. The reproducibility and accuracy of the method was tested by the determination of standard sample solutions (see Table 1 (b)).

Table 1 (a) Instrumental parameters and composition of the electrolyte system for the determination of Ti(IV) by AdSV; (b) determination of standard sample solutions

(a)

\begin{tabular}{|l|l|}
\hline $\begin{array}{l}\text { Deposition potential (vs } \mathrm{Ag} / \mathrm{AgCl}) \\
\mathrm{mV}\end{array}$ & -570 \\
\hline deposition time / s & 60 \\
\hline HMDE surface area / $\mathrm{mm}^{2}$ & 0.68 \\
\hline
\end{tabular}




\begin{tabular}{|l|l|}
\hline pulse amplitude / mV & 60 \\
\hline pulse time / s & 0.1 \\
\hline sweep rate / mV/s & 40 \\
\hline temperature of voltammetric cell $/{ }^{\circ} \mathrm{C}$ & $(25+/-1)$ \\
\hline composition of supporting electrolyte: & $54.6 \mathrm{mM} \mathrm{KClO} 3$ \\
& $4.8 \mathrm{mM}$ mandelic acid \\
& $2.7 \mathrm{mM}$ ammonia \\
\hline
\end{tabular}

(b)

\begin{tabular}{|l|l|}
\hline $\begin{array}{l}\text { titanium(IV) in sample solution (actual) } \\
\text { / nmol/L }\end{array}$ & $\begin{array}{l}\text { titanium(IV) in sample solution (target) } \\
/ \mathrm{nmol} / \mathrm{L}\end{array}$ \\
\hline 1.82 & $1.80+/-0.11$ \\
\hline 4.56 & $4.40+/-0.12$ \\
\hline
\end{tabular}

2.3 XRD investigations

Diffraction patterns of the samples were registered with the device URD-6 (Freiberger Präzisionsmechanik) at a resolution of $0.01^{\circ}$ for $8^{\circ} \leq 2 \Theta \leq 60^{\circ}$. Mo Kalpha radiation was used. The evaluation of the data has been done with the software PowderCell 2.4 [30] by simulation of the diffraction pattern using pseudo Voigt functions and single crystal data from the Inorganic Crystal Structure Database (ICSD) (rutile: ICSD collection Code no. 31322, anatase: no. 31064, brookite: no. 36408). The composition of the samples as well as the mean crystallite diameter have been obtained.

\subsection{Gas sorption measurements}

Nitrogen sorption isotherms of the titania powders were obtained with a volumetric sorption analyzer Autosorb-1 (Quantachrome). In a typical experiment about 200 to $500 \mathrm{mg}$ of the powder were outgassed at $350{ }^{\circ} \mathrm{C}$ for at least 2 hours. Then adsorption and desorption isotherms were recorded at $77 \mathrm{~K}$. The evaluation of the data has been done with the Autosorb 1.0 software (Quantachrome).

2.5 Colloid titration 
Titrations of aqueous dispersions of the powder were performed in order to obtain information about the point of zero charge (pzc). The mass of substance equal to $20 \mathrm{~m}^{2}$ BET surface area was transferred to a vessel of the titration device TR250/Titronic T110 (Schott). $60 \mathrm{~mL}$ of $\mathrm{NaCl}$ solution $(0.001 \mathrm{M}$ to $0.1 \mathrm{M})$ were added and a magnetic stirring bar was used to disperse the powder. The dispersion was continuously purged with argon about 15 minutes prior to and during the titration. The $\mathrm{pH}$ was adjusted to 9.5 by addition of Ar-purged $\mathrm{NaOH}(0.1 \mathrm{M}$, volumetric standard, Aldrich). Then a titration with $\mathrm{HCl}(0.1 \mathrm{M}$, volumetric standard, Aldrich) was performed until a final $\mathrm{pH}$ value smaller than 3 was obtained. Then a blank measurement of $\mathrm{NaCl}$ solution (without solid) after addition of the same amount of $\mathrm{NaOH}$ (Ar-purged) as in the preceding measurement is performed. From these two measurements surface charge density vs. $\mathrm{pH}$ curves can be calculated and the pzc is obtained. Intrinsic dissociation constants of surface hydroxyls of titania have been determined from these data applying the procedure described by Barringer et al. [31].

\section{Results and Discussion}

\subsection{Characteristics of titania nanoparticle samples}

The results on phase composition and specific surface area are summarized in Table 2. The mean crystallite diameter and the average particle diameter determined from the BET surface area $\mathrm{d}_{\mathrm{BET}}$ provide a rough estimate of the primary particle size within larger nanostructured units. All titanias under consideration are large scale products used as e.g. filler components or catalysts and are of pure anatase phase, a mixture of anatase and rutile or a mixture of anatase, and an amorphous phase. They are produced either by flame pyrolysis (P25, Evonik Degussa) or by precipitation (DT51D and G5, Millenium Chemicals). For comparison the solubility of a uncalcined titanium hydrous oxide slurry (TRONOX Hydrate Paste, Tronox) was determined, too. The solid content of the slurry was washed by repeated centrifugation in deionised water and dried at $110{ }^{\circ} \mathrm{C}$ over night prior to characterisation and use in the dissolution experiment. 


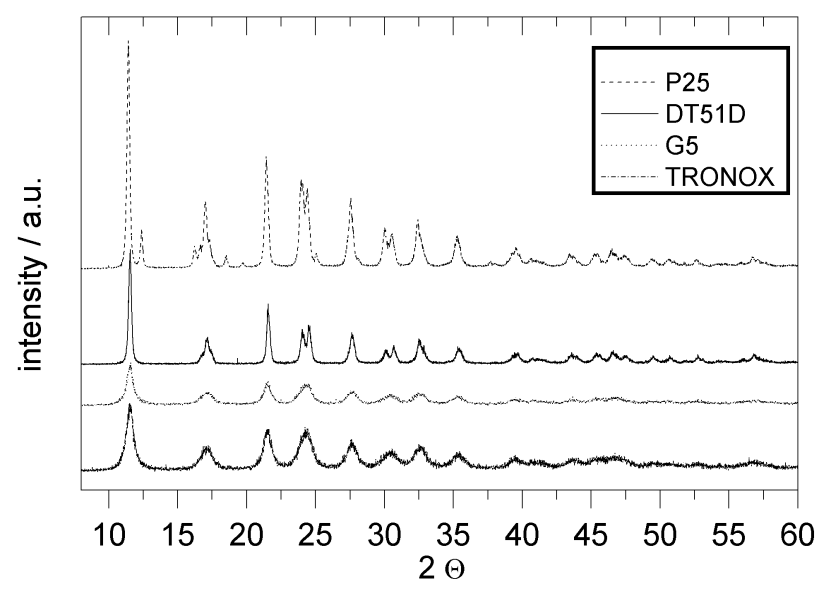

Fig. 1 XRD patterns of different industrially produced titania and titanium hydrous oxide samples XRD (see Fig. 1) reveals, that the samples DT51D and G5 are phase pure anatase, whereas P25 is an anatase and rutile mixture. According to our XRD studies the titanium hydrous oxide sample TRONOX is composed of larger anatase crystallites of about $11 \mathrm{~nm}$ in diameter and smaller anatase crystallites $<5 \mathrm{~nm}$. The fraction of these small crystallites has been defined as X-ray amorphous anatase phase (crystallites $<5 \mathrm{~nm}$ ). The mass fractions have been obtained by simulation of the XRD patterns with the software Powder Cell using single crystal data of anatase. The amorphous phase is simulated by using a widened profile function of the anatase pattern. The crystallite diameters reported have been calculated according to the Scherrer equation from the X-ray pattern.

The XRD results are consistent with Raman results (not shown here). The minimum primary particle size is given by the crystallite diameter determined by XRD. For the sample P25 the primary particle size evaluated from the BET surface area $S_{\mathrm{BET}}$ by assuming spherical particles of uniform size (see Eq.1) compares favourable to the crystallite diameter determined by XRD (calculated with PowderCell 2.4), the other samples show at least qualitative agreement. This is reasonable because of the fact that the assumptions made for the determination of a mean particle diameter $\mathrm{d}_{\mathrm{BET}}$ from BET surface area strictly is only applicable in the case of non-porous samples, while DT51D is mesoporous and G5 and TRONOX show micro- and mesoporosity (see Fig. 2). A density $\rho$ of $3.8 \mathrm{~g} / \mathrm{cm}^{3}$ has been used for an estimate of $\mathrm{d}_{\mathrm{BET}}$ (see Eq. 1).

$d_{B E T}=\frac{6}{S_{B E T} \cdot \rho}$ 
Table 2 Phase composition (XRD) and BET surface area (nitrogen sorption, $77 \mathrm{~K}$ ) of different titanium dioxide nanoparticles and titanium hydrous oxide

\begin{tabular}{|c|c|c|c|c|c|}
\hline sample & $\begin{array}{l}\text { phase } \\
\text { composition } \\
\text { (XRD) / phase } \\
(\text { wt.-\%) }\end{array}$ & $\begin{array}{l}\text { crystallite } \\
\text { diameter / } \\
\text { nm }\end{array}$ & $\begin{array}{l}\text { BET surface area } \\
\mathrm{S}_{\mathrm{BET}} / \mathrm{m}^{2} / \mathrm{g} ; \\
\text { (correlation } \\
\text { coefficient of } \\
\text { BET evaluation) }\end{array}$ & $\begin{array}{l}\text { micropore } \\
\text { surface area } \\
\text { (t-method) / } \\
\mathrm{m}^{2} / \mathrm{g}\end{array}$ & $\begin{array}{l}\text { mean particle } \\
\text { diameter calculated } \\
\text { from } \mathrm{BET} \text { surface } \\
\text { area } \mathrm{d}_{\mathrm{BET}} / \mathrm{nm}\end{array}$ \\
\hline $\begin{array}{l}\text { P25 (Evonik } \\
\text { Degussa) }\end{array}$ & $\begin{array}{l}\text { anatase (86) } \\
\text { rutile (14) }\end{array}$ & $\begin{array}{l}24.4 \\
\text { (anatase) } \\
29.7 \\
\text { (rutile) }\end{array}$ & $\begin{array}{l}55.7 \\
\left(\mathrm{R}^{2}=0.999910\right)\end{array}$ & - & 28.3 \\
\hline $\begin{array}{l}\text { DT51D } \\
\text { (Millenium } \\
\text { Chemicals) }\end{array}$ & anatase (100) & 23.9 & $\begin{array}{l}88.5 \\
\left(\mathrm{R}^{2}=0.999944\right)\end{array}$ & - & 17.8 \\
\hline $\begin{array}{l}\text { G5 } \\
\text { (Millenium } \\
\text { Chemicals) }\end{array}$ & anatase (100) & 9.7 & $\begin{array}{l}332.5 \\
\left(\mathrm{R}^{2}=0.999755\right)\end{array}$ & 168.7 & 4.7 \\
\hline $\begin{array}{l}\text { TRONOX } \\
\text { Hydrate Paste } \\
\text { (Tronox) }\end{array}$ & $\begin{array}{l}\text { anatase (29) } \\
\text { amorphous (71) }\end{array}$ & $\begin{array}{l}11.3 \\
\text { (anatase) } \\
4.7 \text { (amor- } \\
\text { phous) }\end{array}$ & $\begin{array}{l}302.5 \\
\left(\mathrm{R}^{2}=0.999559\right)\end{array}$ & 119.6 & 5.2 \\
\hline
\end{tabular}

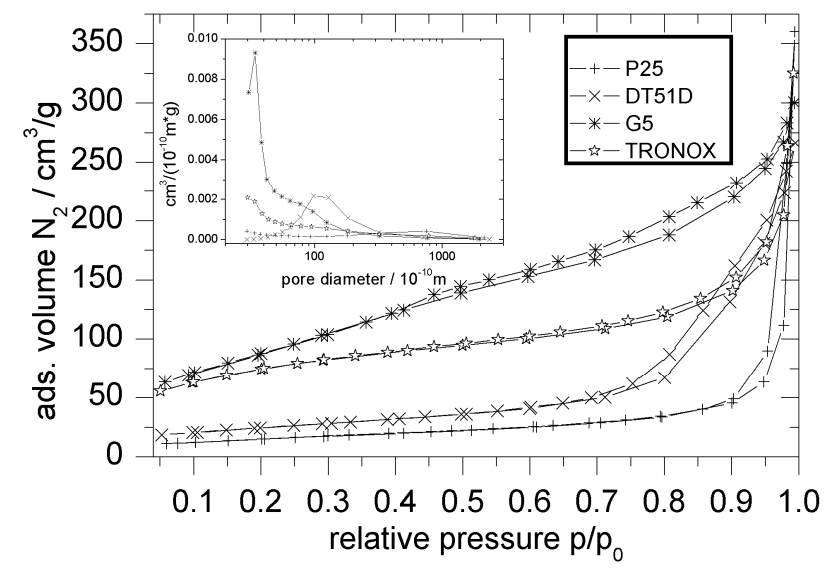

Fig. 2 Nitrogen sorption isotherms of crystalline and hydrous titania samples and desorption pore size distribution (BJH method)

3.2 Surface charge density and point of zero charge

Solubility is strongly influenced by the surface charge of the respective oxide in aqueous environment [32]. A solid is expected to show minimum solubility in the 
vicinity of its point of zero charge (pzc). Therefore the determination of surface charge densities by colloid titration may be useful to obtain information about the surface charge state in dependence on $\mathrm{pH}$. Moreover intrinsic dissociation constants for the surface hydroxyls of $\mathrm{TiO}_{2}$ can be extrapolated from these data [31].

The surface charge of titania results according to the $2 \mathrm{pK}$-model from charged surface sites formed by the following protolysis reactions:

$$
\begin{aligned}
& \equiv \mathrm{Ti}-\mathrm{OH}_{2}{ }^{+} \leftrightarrow \equiv \mathrm{Ti}-\mathrm{OH}+\mathrm{H}^{+} ; K_{s, 1}=\frac{[\equiv \mathrm{TiOH}] \cdot\left[\mathrm{H}^{+}\right]}{\left[\equiv \mathrm{Ti}-\mathrm{OH}_{2}^{+}\right]}=K^{0}{ }_{s, 1} \cdot \exp \left(Y_{0}\right) \\
& \equiv \mathrm{Ti}-\mathrm{OH} \leftrightarrow \equiv \mathrm{Ti}-\mathrm{O}^{-}+\mathrm{H}^{+} ; K_{s, 2}=\frac{\left[\equiv \mathrm{TiO} \mathrm{O}^{-}\right] \cdot\left[\mathrm{H}^{+}\right]}{[\equiv \mathrm{Ti}-\mathrm{OH}]}=K_{s, 2}^{0} \cdot \exp \left(Y_{0}\right)
\end{aligned}
$$

The equilibrium constants $\mathrm{K}$ with superscript 0 represent intrinsic equilibrium constants. $\mathrm{Y}_{0}$ represents the normalized dimensionless surface potential.

In Fig. 3 surface charge density $\left(\sigma_{0}\right)$ vs. $\mathrm{pH}$ curves for the three titanium dioxides studied and an amorphous titanium hydrous oxide (at $25^{\circ} \mathrm{C}$ ) are presented. It can be clearly seen that the pzc for anatase (DT51D, G5) is found at pH 5.8 to 6.1 (see Table 3). This result is in agreement with most of the findings in literature. Kosmulski [33] proposes in his review on the point of zero charge of anatase and rutile a pzc of 5.9 for the both polymorphs. The pzc calculated as $\mathrm{pzc}=0.5^{*}\left(\mathrm{pK}_{\mathrm{s}, 1}^{0}\right.$ $+\mathrm{pK}_{\mathrm{s}, 2}^{0}$ ) from the intrinsic dissociation constants of surface hydroxyls given by Barringer et al. [31] gives more or less the same pzc of 5.9 and 5.95 for anatase and rutile. The pzc found for P25 and TRONOX is slightly higher and lower, respectively, than the value observed for anatase DT51D. A shift to a lower pzc for amorphous titania samples like TRONOX is known. Small deviations in the pzc-values can be explained qualitatively by the multi site complexation model suggested recently [34]. This model considers different coordinated $\mathrm{Ti}-\mathrm{O}$ groups in crystalline rutile and anatase. In the framework of the model a pzc for rutile of 5.9 is reported, too, but $\log \mathrm{K}$ values of 7.5 and 4.4 (singly and doubly coordinated surface groups) are obtained. A change of the proportion of these groups is obviously the case in mixtures of the two polymorphs but it may also play a role if the particles become very small. The intrinsic dissociation constants 
obtained from our colloid titration data show the qualitative behaviour expected with respect to the distinction between amorphous titania and anatase.
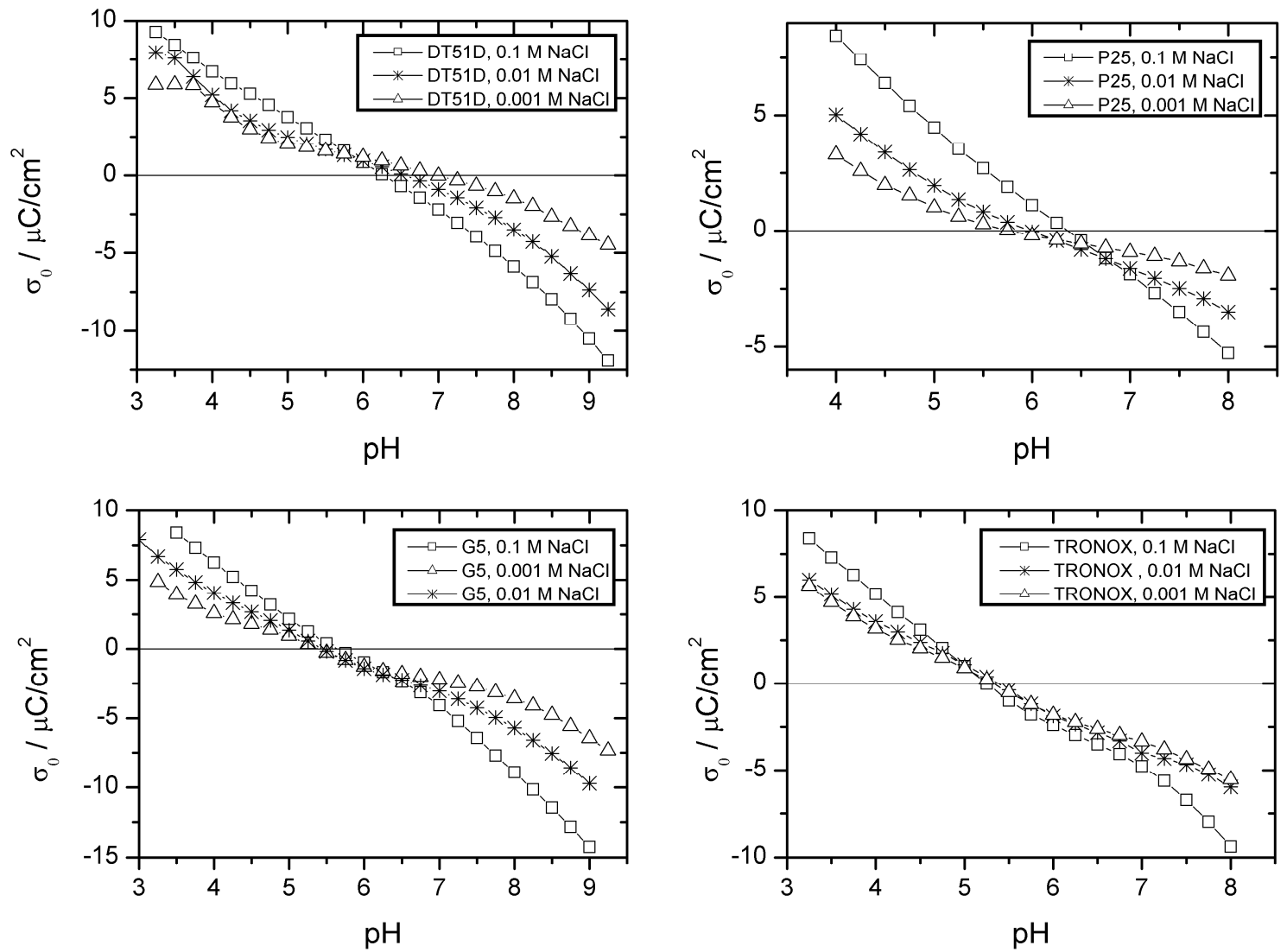

Fig. 3 Surface charge density vs. pH plots of crystalline and hydrous titania samples

Table 3 pzc and intrinsic surface hydroxyl dissociation constants of industrially produced titanias and hydrous titanium oxide obtained by colloid titration

\begin{tabular}{|l|l|l|l|}
\hline sample & $\mathrm{pzc}$ & $\mathrm{pK}_{\mathrm{s}, 1}^{0}$ & $\mathrm{pK}_{\mathrm{s}, 2}^{0}$ \\
\hline DT51D (anatase) & $5.8+/-0.1$ & 2.5 & 9.2 \\
\hline G5 (anatase) & $6.1+/-0.3$ & 2.6 & 9.4 \\
\hline P25 (anatase, rutile) & $6.5+/-0.3$ & 3.2 & 10.1 \\
\hline TRONOX (amorphous, anatase) & $5.3+/-0.4$ & 2.5 & 7.9 \\
\hline Literature (Barringer et al. [31]) & & & \\
\hline rutile & 5.9 & 2.7 & 9.1 \\
\hline anatase & 5.95 & 3.2 & 8.7 \\
\hline amorphous titania & 5.2 & 2.0 & 8.4 \\
\hline
\end{tabular}

3.3 Aqueous solubility of anatase nanoparticles DT51D in dependence on time 
The solubility of DT51D (anatase) nanoparticles in dependence on dissolution time is depicted in figure 4 for different $\mathrm{pH}$ in $0.1 \mathrm{M} \mathrm{NaCl}$. It is noteworthy that during the first 70 hours after starting the dissolution experiment the titanium(IV) concentrations observed exceed the saturation solubility (dissolution time $>500 \mathrm{~h}$ ) considerably. This behaviour has been observed earlier for different substances [14-16] and explained in the framework of a phenomenological dissolution model [35] as a kinetic size effect, which is a general characteristic behaviour of nanoparticulate matter. Kinetic size effect is not subject of this paper, for details please see refs. 35 and 14-16. It has been established that for dissolution times of more than 500 hours (see Fig. 4) the amount of titanium(IV) dissolved does not change within the accuracy of the determination method. Therefore these longterm solubilities ( $\geq 500 \mathrm{~h}$ dissolution time) can be used as a good estimate of equilibrium solubility under these dissolution conditions.

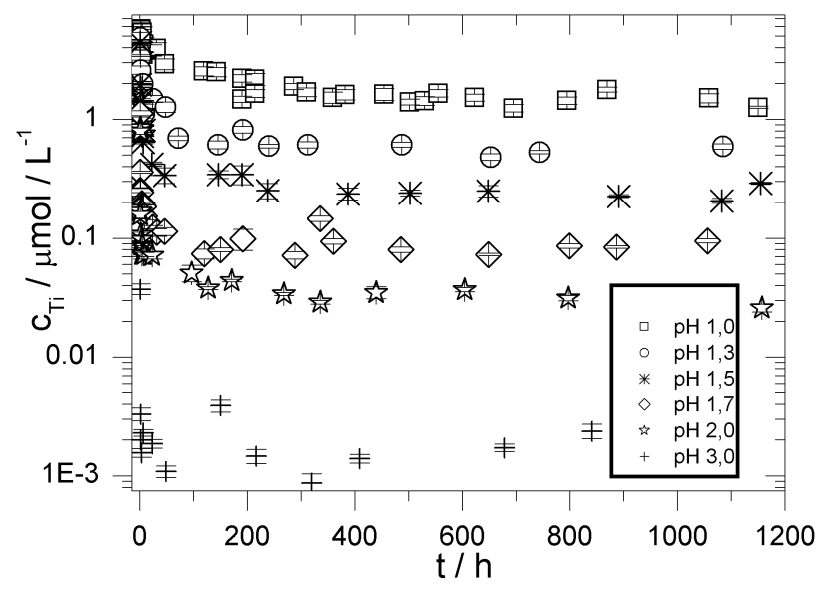

Fig. 4 Titanium(IV) dissolved in dependence on $\mathrm{pH}$ and dissolution time $\left(40 \mathrm{~m}^{2} / 100 \mathrm{~mL}\right.$ DT51D (anatase); $0.1 \mathrm{M} \mathrm{NaCl} ; 25^{\circ} \mathrm{C}$ )

$3.4 \mathrm{pH}$ dependence of the long-term solubility of titania nanoparticles

The aqueous solubilities of the different titania samples for dissolution times of more than 500 hours in dependence on $\mathrm{pH}$ are shown in Fig. 5. First, the pure anatase sample DT51D, the anatase rutile mixture P25, as well as a pure bulk rutile sample (RL11A, Millenium Chemicals) consisting of micron-sized primary particles and a bulk anatase sample (AT1, Millenium Chemicals; solubility data for RL11A and AT1 not shown here) have comparable long-term solubilities. Only in the case of G5 a pronounced size effect on the long-term solubility of anatase can be observed in the acidic pH range (see Fig. 5). This behaviour can be 
explained in terms of the dependence of solubility on curvature (Kelvin equation): small particles show higher solubility compared to larger ones. G5 which exhibits higher aqueous solubility with respect to P25 or DT51D consists of the smallest primary particles of the anatase samples under consideration in this study.

Lencka et al. [36] argued from thermodynamic data that rutile should be less soluble than anatase, but this behaviour could not be observed experimentally (no significant difference in solubility within the limits of error of the determination method). Rutile is the thermodynamic more stable phase compared to anatase, but one has to keep in mind that the free energy of formation of anatase and rutile reported does not differ significantly. Therefore pronounced differences in solubility of these two polymorphs are not expected to occur.

The long-term solubility data of P25, and DT51D can be used as an appropriate estimate for the bulk equilibrium solubility of titania. In the case of the sample G5 the solubility determined is the increased solubility of nanoparticles due to the Kelvin effect.

No significant change in BET surface area, i.e. no significant change in mean primary particle size, of the titanium dioxide samples DT51D, P25 and G5 exposed to dissolution has been observed within the time frame of the dissolution experiment (see Figure 6; for a representation of BET surface area in dependence on $\mathrm{pH}$ of dissolution and dissolution time see table $\mathrm{A}$ in the electronic supplementary material). We also performed SEM studies with the sample G5. Possible changes due to dissolution processes -if any- should be most clearly noticeable with this sample. Actually there are only minor changes of the morphology of the sample G5 (see figures A to I in the electronic supplementary material). 


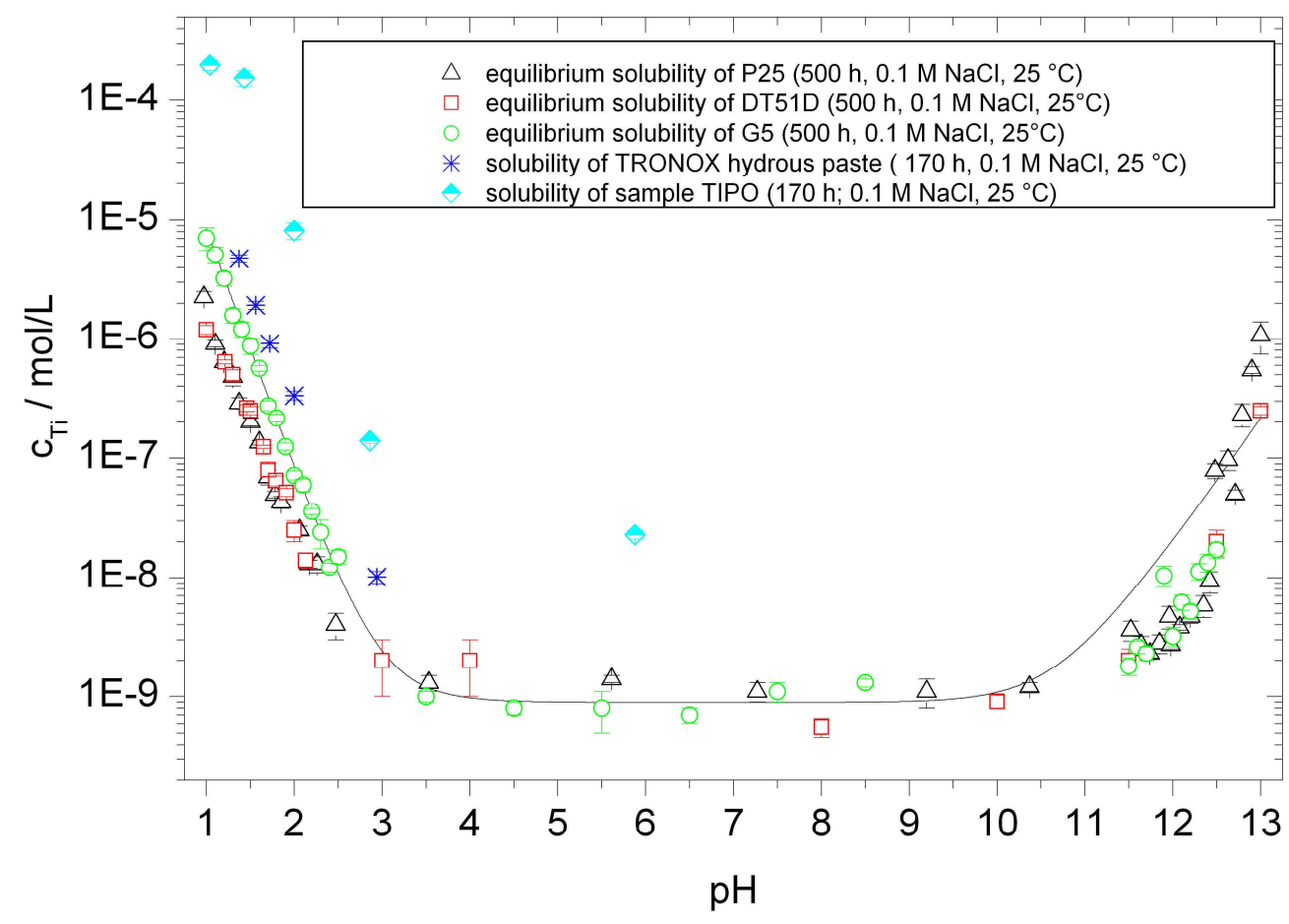

Fig 5 Solubility of crystalline titania (P25, DT51D, G5) and amorphous titanium hydrous oxides (TRONOX, TIPO) in dependence on $\mathrm{pH}\left(0.1 \mathrm{M} \mathrm{NaCl} ; 25^{\circ} \mathrm{C}\right)$ determined by AdSV; solid line: solubility of titanium dioxide $\left(\mathrm{I}=0.1 ; 25^{\circ} \mathrm{C}\right)$ calculated with the equilibrium constants determined in this study

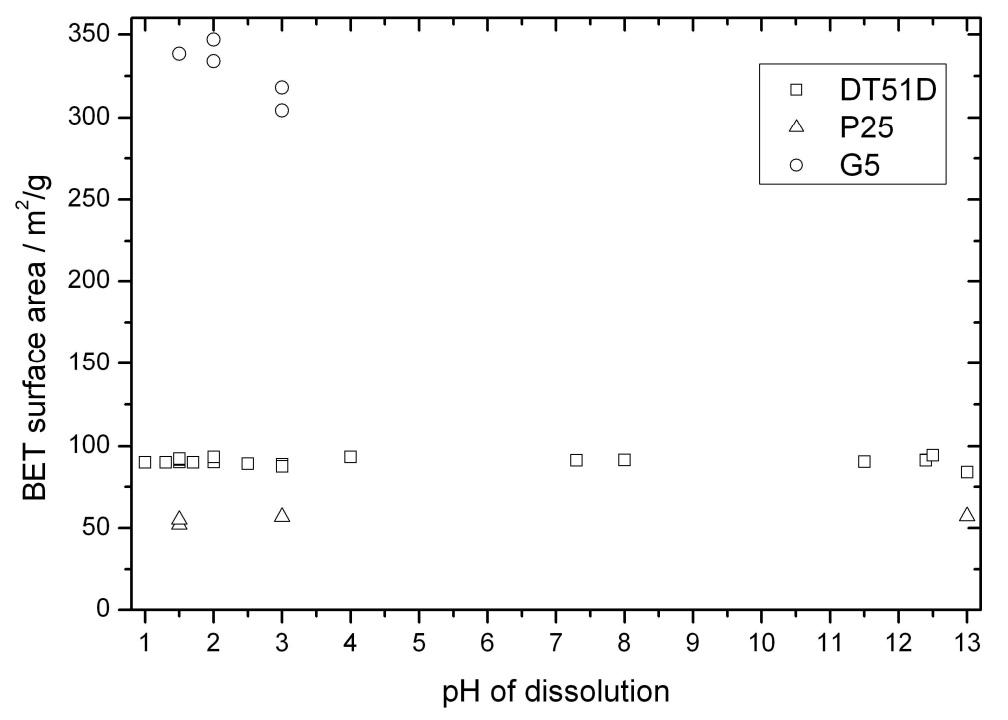




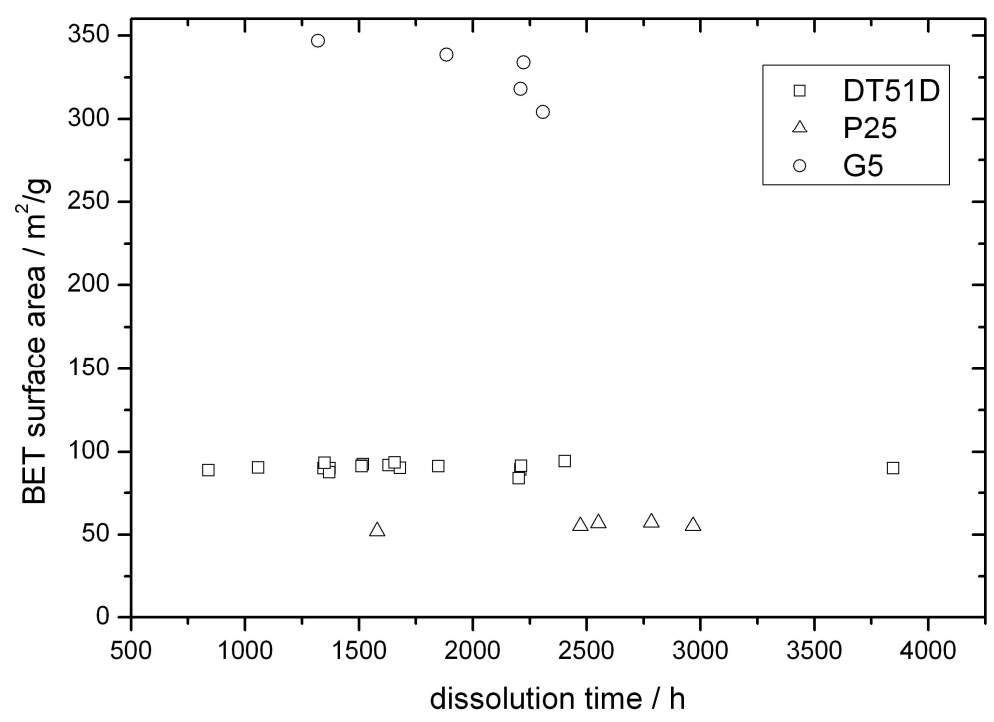

Fig 6 BET surface area of DT51D, P25, G5 for different $\mathrm{pH}$ values and dissolution times

This is interpreted in terms that the difference in Gibbs free energy between the two systems titania nanoparticles - electrolyte solution and bulk titania electrolyte solution, i.e. the "driving force" for particle growth, at this stage of the dissolution process is low. Therefore we can conclude that the long-term solubilities observed for the nanoparticulate titanias P25 and DT51D are not significantly increased with respect to bulk titania, although the "real" equilibrium solubility of bulk titania may be somewhat lower. Nevertheless our observation that the long-term solubility of the oxides under consideration and that the solubility of micron-sized titania are comparable supports the validity of this estimate.

The solubility data were modelled under the assumption that the total $\mathrm{pH}$ dependent concentration of titanium(IV) dissolved $\mathrm{c}(\mathrm{Ti})_{\text {total }}(\mathrm{pH})$ is distributed on mononuclear titanium hydroxo complexes of the general formula $\left[\mathrm{Ti}(\mathrm{OH})_{\mathrm{n}}\right]^{(4-\mathrm{n})+}$ :

$c(T i)_{\text {total }}(p H)=\sum_{n=2}^{5} c\left(\left[\operatorname{Ti}(\mathrm{OH})_{n}\right]^{(4-n)+}\right)$

In the approach presented in Eq. 2 the species $\mathrm{Ti}(\mathrm{OH})_{2}{ }^{2+}, \mathrm{Ti}(\mathrm{OH})_{3}{ }^{+}, \mathrm{Ti}(\mathrm{OH})_{4}$ and $\mathrm{Ti}(\mathrm{OH})_{5}{ }^{-}$are taken into account. The consideration of higher charged species like $\mathrm{Ti}(\mathrm{OH})^{3+}$ or " $\mathrm{Ti}^{4+}$ " in the $\mathrm{pH}$ range studied is not necessary as they are not expected to exist under these conditions. Moreover in calculations according to Eq. 2 when taking into account these species (i.e. $n=0$ to 5 ) it turns out that $n=0$, 1 do not have to be considered. The titanium hydroxo complexes are connected via consecutive hydrolysis reactions that are dependent on $\mathrm{pH}$ : 
$\left[\mathrm{Ti}(\mathrm{OH})_{n}\right]^{(4-n)+} \longleftrightarrow\left[\mathrm{Ti}(\mathrm{OH})_{n-1}\right]^{(5-n)+}+\mathrm{OH}^{-}$

As only the total amount of titanium dissolved as function of dissolution $\mathrm{pH}$ is known, but there are four unknown equilibrium constants (including the solubility product of $\mathrm{TiO}_{2}$ ) equation 2 is an under-determined formula, i.e. there does not exist an unique solution. Therefore the fitting procedure (Levenberg-Marquardt algorithm; all calculations have been performed with the computer algebra system Mathematica [37]) was done with estimated values for the equilibrium constants of stepwise hydrolysis that have been obtained from a preceding modelling of the dependence of titanium(IV) dissolved on $\mathrm{pH}$ for distinct $\mathrm{pH}$-ranges, where the simplification can be made that only two species are prominent and therefore a determined equation for the $\mathrm{pH}$ dependence of the total titanium(IV) concentration is obtainable. Reasonable results are achieved by this procedure. The same procedure was also applied for determining cumulative hydrolysis constants. The cumulative equilibrium constants determined by fitting the solubility data of P25, DT51D and G5 corrected for activity effects of the supporting electrolyte system according to Davies (Eq. 4) [38] are summarized in Table 4 . The confidence intervals presented there are obtained by nonlinear fitting the overall experimental solubility data according to Eq. 2 taking the activity coefficients into account calculated according to the empirical Davies' approximation (Eq. 4). In Eq. $4 \gamma_{\mathrm{i}}$ represents the activity coefficient of the aqueous species $\mathrm{i}$ of charge $\mathrm{z}_{\mathrm{i}}$; I represents the ionic strength and $\mathrm{A}=0.5102$ at $25{ }^{\circ} \mathrm{C}$.

$\log \gamma_{i}=-A \cdot z_{i}^{2} \cdot\left(\frac{\sqrt{I}}{1+\sqrt{I}}-0.3 \cdot I\right)$

Table 4 Cumulative hydrolysis constants of titania ( $\mathrm{I}=0 ; 298 \mathrm{~K}$ ) derived from solubility measurements of different industrially produced titanium dioxide nanoparticles

\begin{tabular}{|l|l|l|}
\hline & Log $(\mathrm{K})$ & Confidence interval 95\% \\
\hline $\mathrm{P} 25(\mathrm{~N}=35$ data points $)$ & & \\
\hline $\mathrm{TiO}_{2}+2 \mathrm{H}^{+}=\mathrm{Ti}(\mathrm{OH})_{2}{ }^{2+}$ & -3.55 & -3.91 to -3.19 \\
\hline $\mathrm{TiO}_{2}+\mathrm{H}^{+}+\mathrm{H}_{2} \mathrm{O}=\mathrm{Ti}(\mathrm{OH})_{3}{ }^{+}$ & -6.15 & -7.37 to -4.93 \\
\hline $\mathrm{TiO}_{2}+2 \mathrm{H}_{2} \mathrm{O}=\mathrm{Ti}(\mathrm{OH})_{4}$ & -9.02 & -9.41 to -8.63 \\
\hline $\mathrm{TiO}_{2}+3 \mathrm{H}_{2} \mathrm{O}=\mathrm{Ti}(\mathrm{OH})_{5}{ }^{-}+\mathrm{H}^{+}$ & -19.83 & -20.05 to -19.61 \\
\hline & & \\
\hline
\end{tabular}




\begin{tabular}{|l|l|l|}
\hline DT51D $(\mathrm{N}=18)$ & & \\
\hline $\mathrm{TiO}_{2}+2 \mathrm{H}^{+}=\mathrm{Ti}(\mathrm{OH})_{2}{ }^{2+}$ & -3.56 & -3.80 to -3.36 \\
\hline $\mathrm{TiO}_{2}+\mathrm{H}^{+}+\mathrm{H}_{2} \mathrm{O}=\mathrm{Ti}(\mathrm{OH})_{3}{ }^{+}$ & -5.93 & -6.50 to -5.36 \\
\hline $\mathrm{TiO}_{2}+2 \mathrm{H}_{2} \mathrm{O}=\mathrm{Ti}(\mathrm{OH})_{4}$ & -9.07 & -9.33 to -8.81 \\
\hline $\mathrm{TiO}_{2}+3 \mathrm{H}_{2} \mathrm{O}=\mathrm{Ti}(\mathrm{OH})_{5}{ }^{-}+\mathrm{H}^{+}$ & -19.78 & -20.05 to -19.52 \\
\hline & & \\
\hline $\mathrm{G5}(\mathrm{N}=32)$ & & -2.97 to -2.80 \\
\hline $\mathrm{TiO}_{2}+2 \mathrm{H}^{+}=\mathrm{Ti}(\mathrm{OH})_{2}{ }^{2+}$ & -2.88 & -5.30 to -7.23 \\
\hline $\mathrm{TiO}_{2}+\mathrm{H}^{+}+\mathrm{H} \mathrm{H}_{2} \mathrm{O}=\mathrm{Ti}(\mathrm{OH})_{3}{ }^{+}$ & -6.27 & -9.16 to -8.95 \\
\hline $\mathrm{TiO}_{2}+2 \mathrm{H}_{2} \mathrm{O}=\mathrm{Ti}(\mathrm{OH})_{4}$ & -9.06 & -20.23 to -20.04 \\
\hline $\mathrm{TiO}_{2}+3 \mathrm{H}_{2} \mathrm{O}=\mathrm{Ti}(\mathrm{OH})_{5}{ }^{-}+\mathrm{H}^{+}$ & -20.14 & \\
\hline
\end{tabular}

The aqueous speciation shown in figure 7 can be calculated from the equilibrium data given in Table 5. It can be seen from the experimentally obtained equilibrium constants (tables 4 and 5) and the solubility data (Fig. 5) that the species $\mathrm{Ti}(\mathrm{OH})_{2}{ }^{2+}\left(\right.$ or $\left.\mathrm{TiO}^{2+}\right)$ is prominent in the acidic $\mathrm{pH}$-range and that it determines the solubility of titania under these conditions. In the intermediate $\mathrm{pH}$-range 3 to 11 the solubility of titania is limited to about $1 * 10^{-9} \mathrm{~mol} / \mathrm{L}$ (at $0.1 \mathrm{M} \mathrm{NaCl}$ ); the neutral complex ion $\mathrm{Ti}(\mathrm{OH})_{4}$ is predominant. At very alkaline conditions solubility data indicate the formation of an anionic complex ion $\mathrm{Ti}(\mathrm{OH})_{5}{ }^{-}$(or $\mathrm{HTiO}_{3}{ }^{-}$.

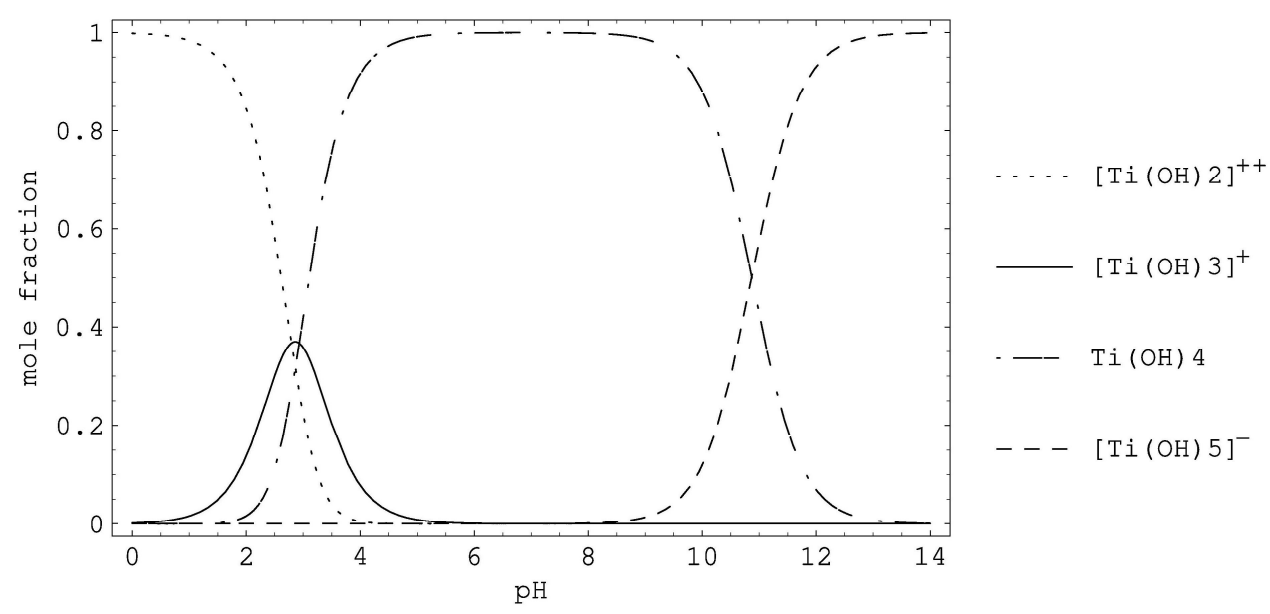

Fig 7 Speciation of Ti(IV) in solutions in contact with solid titania (assuming hydroxo complexes of titanium the only species to be present) in dependence on $\mathrm{pH}\left(25^{\circ} \mathrm{C}, \mathrm{I}=0\right)$ 
The effect of the degree of hydroxylation on the solubility of titanium oxide is obvious when comparing samples DT51D, G5, P25 with TRONOX and TIPO. The sample TIPO has been prepared by the hydrolysis of $5 \mathrm{~mL}$ titanium tetraisopropoxide (TTIP) in $50 \mathrm{~mL}$ aqueous solution (about $0.1 \mathrm{M} \mathrm{NaCl}$ ) of the appropriate dissolution $\mathrm{pH}$ (adjusted by addition of small volumes of $\mathrm{HCl}$ or $\mathrm{NaOH}$ ). Instantly after the addition of TTIP to the aqueous solution a precipitate (mainly an amorphous solid with small fractions of crystallites of the rutile or anatase phase respectively, as revealed by XRD after separation) is formed. 170 hours after hydrolysis of TTIP the titanium(IV) dissolved in the supernatant solutions has been determined. It is found that these solutions are supersaturated with Ti(IV) with respect to crystalline titanium dioxide (anatase). The uncalcined titanium hydrous oxide TRONOX (70 \% amorphous phase) shows increased solubility with respect to crystalline titania (P25, DT51D), too (see Fig. 5). The freshly prepared sample TIPO is more soluble than the uncalcined hydrous oxide TRONOX (dried at $110^{\circ} \mathrm{C}$ ), whereas crystalline titanium dioxide nanoparticles have the lowest solubility. Therefore we can conclude that in dissolution experiments with samples that have high amorphous phase content and degree of hydroxylation higher aqueous titanium(IV) solubility will be observed. It is established that oxides that have very hydroxylated surfaces will show a higher solubility compared to less hydroxylated ones. In general amorphous matter of a certain compound will have higher solubility than the well crystallised solid.

It should be emphasized, that when comparing or reporting solubilities the effects of dissolution time (attainment of dissolution equilibria), primary particles size (Kelvin effect) and of hydroxylation and hydration of the solid have to be taken into account.

We propose to use the mean of the equilibrium constants for the respective hydrolysis reaction of the three crystalline titania samples (P25, DT51D, G5) under consideration as equilibrium constants for the hydrolysis of titania in general (Table 6). The standard deviation of the mean $\log (\mathrm{K})$ that is calculated from the respective equilibrium constants for the three datasets can be used as an estimate for the errors of the hydrolysis constants presented here.

Table 5 Proposed stepwise and cumulative equilibrium constants for the hydrolysis of titania (I=0; $298 \mathrm{~K}$ ) derived from solubility measurements (see figures 5 to 7 ) 


\begin{tabular}{|l|l|l|}
\hline & Mean Log $(\mathrm{K})$ & $\begin{array}{l}\text { Standard deviation } \\
\text { Log }(\mathrm{K})\end{array}$ \\
\hline $\mathrm{Ti}(\mathrm{OH})_{2}{ }^{2+}+\mathrm{OH}^{-}=\mathrm{Ti}(\mathrm{OH})_{3}{ }^{+}$ & 12.15 & 0.43 \\
\hline $\mathrm{Ti}(\mathrm{OH})_{3}{ }^{+}+\mathrm{OH}^{-}=\mathrm{Ti}(\mathrm{OH})_{4}$ & 11.05 & 0.20 \\
\hline $\mathrm{Ti}(\mathrm{OH})_{4}+\mathrm{OH}^{-}=\mathrm{Ti}(\mathrm{OH})_{5}{ }^{-}$ & 2.91 & 0.19 \\
\hline $\mathrm{TiO}_{2}+2 \mathrm{H}^{+}=\mathrm{Ti}(\mathrm{OH})_{2}{ }^{+}$ & -3.33 & 0.39 \\
\hline $\mathrm{TiO}_{2}+\mathrm{H}^{+}+\mathrm{H}_{2} \mathrm{O}=\mathrm{Ti}(\mathrm{OH})_{3}{ }^{+}$ & -6.12 & 0.17 \\
\hline $\mathrm{TiO}_{2}+2 \mathrm{H}_{2} \mathrm{O}=\mathrm{Ti}(\mathrm{OH})_{4}$ & -9.05 & 0.03 \\
\hline $\mathrm{TiO}_{2}+3 \mathrm{H}_{2} \mathrm{O}=\mathrm{Ti}(\mathrm{OH})_{5}+\mathrm{H}^{+}$ & -19.92 & 0.20 \\
\hline
\end{tabular}

\section{Conclusions}

The $\mathrm{pH}$-dependent equilibrium solubility of titanium dioxide at $298 \mathrm{~K}$ has been approximated by the long-term solubilities ( $\geq 500 \mathrm{~h}$ ) of industrially produced anatase samples. The quantitative determination of titanium(IV) dissolved has been carried out by AdSV in the mandelic acid - potassium chlorate system [28] and the reproducibility and accuracy of this method as well as an appropriate sampling procedure have been established [29].

Titania shows at $298 \mathrm{~K}(0.1 \mathrm{M} \mathrm{NaCl})$ solubilities as low as about $1 \mathrm{nmol} / \mathrm{l}$ in the intermediate $\mathrm{pH}$-range ( $\mathrm{pH} 3$ to 11), whereas solubilities in the range of 1 to 2 $\mu \mathrm{mol} / \mathrm{l}$ are observed at about $\mathrm{pH} 1$. The standard Gibbs free energies for the stepwise hydrolysis reactions of titanium hydroxyl complexes calculated from the equilibrium constants as well as existing literature data are summarized in Table 6.

Table 6 Comparison of Gibbs free energies for the hydrolysis of titanium hydroxo species reported by different authors

\begin{tabular}{|c|c|c|c|c|}
\hline & \multicolumn{4}{|l|}{$\Delta_{\mathrm{R}} \mathrm{G}^{0} / \mathrm{kJ} / \mathrm{mol}$} \\
\hline reaction & this work & $\begin{array}{l}\text { Ziemniak et } \\
\text { al. [17] }\end{array}$ & $\begin{array}{l}\text { Knauss et } \\
\text { al. [18] }\end{array}$ & $\begin{array}{l}\text { Nabivanets } \\
\text { et al. [24] }\end{array}$ \\
\hline $\begin{array}{l}\mathrm{Ti}(\mathrm{OH})_{2}{ }^{2+}+\mathrm{OH}^{-}= \\
\mathrm{Ti}(\mathrm{OH})_{3}{ }^{+}\end{array}$ & $-69.3+/-2.5$ & -66.8 & - & -71.3 \\
\hline $\begin{array}{l}\mathrm{Ti}(\mathrm{OH})_{3}^{+}+\mathrm{OH}^{-}= \\
\mathrm{Ti}(\mathrm{OH})_{4}\end{array}$ & $-63.0+/-1.1$ & -69.0 & -69.5 & -62.8 \\
\hline
\end{tabular}




\begin{tabular}{|c|c|c|c|c|}
\hline $\begin{array}{l}\mathrm{Ti}(\mathrm{OH})_{4}+\mathrm{OH}^{-}= \\
\mathrm{Ti}(\mathrm{OH})_{5}^{-}\end{array}$ & $-16.6+/-1.1$ & $-9.4+/-1.2$ & -11.5 & - \\
\hline $\begin{array}{l}\mathrm{TiO}_{2}+2 \mathrm{H}^{+}= \\
\mathrm{Ti}(\mathrm{OH})_{2}{ }^{2+}\end{array}$ & $19.0+/-2.2$ & 27.3 & - & - \\
\hline $\begin{array}{l}\mathrm{TiO}_{2}+\mathrm{H}^{+}+\mathrm{H}_{2} \mathrm{O}= \\
\mathrm{Ti}(\mathrm{OH})_{3}^{+}\end{array}$ & $34.9+/-1.0$ & 40.5 & 33.3 & - \\
\hline $\begin{array}{l}\mathrm{TiO}_{2}+2 \mathrm{H}_{2} \mathrm{O}= \\
\mathrm{Ti}(\mathrm{OH})_{4}\end{array}$ & $51.63+/-0.17$ & $\begin{array}{l}51.40 \quad+/- \\
0.23\end{array}$ & 43.5 & - \\
\hline $\begin{array}{l}\mathrm{TiO}_{2}+3 \mathrm{H}_{2} \mathrm{O}= \\
\mathrm{Ti}(\mathrm{OH})_{5}{ }^{-}+\mathrm{H}^{+}\end{array}$ & $113.7+/-1.1$ & 121.9 & 112.0 & - \\
\hline
\end{tabular}

If necessary, data on the free enthalpies of reaction were converted with the standard free energies of formation $\Delta \mathrm{G}_{\mathrm{f}}^{0}\left(\mathrm{H}_{2} \mathrm{O}\right)=-237,19 \mathrm{~kJ} / \mathrm{mol}$ and $\Delta \mathrm{G}_{\mathrm{f}}^{0}\left(\mathrm{OH}^{-}\right)=$$157,3 \mathrm{~kJ} / \mathrm{mol}[17,36]$. The standard Gibbs free energy $\Delta_{\mathrm{R}} \mathrm{G}^{0}=(51.63+/-0.17)$ $\mathrm{kJ} / \mathrm{mol}$ for the dissolution of $\mathrm{TiO}_{2}$ obtained leading to the formation of the aqueous species $\mathrm{Ti}(\mathrm{OH})_{4}$ is in very good agreement with the value reported by Ziemniak et al. for the dissolution of rutile. In our experiments no significant difference in aqueous solubility of anatase and rutile (experiments at $\mathrm{pH} 1.5$ / 1.7 12.0) has been observed. The standard Gibbs free energies for stepwise hydrolysis of titanium hydroxo species obtained in this study are reasonably comparable to previous results (see Table 7). The solubility product of titania determined in this work is $10^{-9.05+/-0.03}$. The degree of hydroxylation of the titanium (hydrous) oxide phase -besides size-effects- strongly influences the aqueous solubilities observed. The equilibrium dissolution data of titania nanoparticles in a sodium chloride system reported here provide an estimate of baseline solubility of $\mathrm{TiO}_{2}$ in aqueous environment.

\section{Acknowledgments}

The XRD measurements are carried out by Dr. B. Müller of Friedrich-SchillerUniversity Jena. This is gratefully acknowledged. 


\section{References}

1. Grätzel, M.: Photoelectrochemical Cells. Nature 414, 338-344 (2001)

2. Zhang, Z., Wang, C., Zakaria, R., Ying, J.Y.: Role of Particle Size in Nanocrystalline $\mathrm{TiO}_{2}$-Based Photocatalysts. J. Phys. Chem. B 102, 1087110878 (1998)

3. Holleman, A.F., Wiberg, N.: Lehrbuch der Anorganischen Chemie / Holleman-Wiberg. de Gruyter, Berlin, New York (1995)

4. Borm, P., Klaessig, F.C., Landry, T.D., Moudgil, B., Pauluhn, J., Thomas, K., Trottier, R., Wood, S.: Research strategies for safety evaluation of nanomaterials, Part V: Role of dissolution in biological fate and effects of nanoscale particles. Tox. Sci. 90, 23-32 (2006)

5. Oberdörster, G., Oberdörster, E., Oberdörster, J.: Nanotoxicology: An Emerging Discipline Evolving from Studies of Ultrafine Particles. Environ. Health Perspect. 113, 823-839 (2005)

6. Nel, A., Xia, T., Mädler, L., Li, N.: Toxic Potential of Materials at the Nanolevel. Science 311, 622-627 (2006)

7. Finnegan, M.P., Zhang, H., Banfield, J.F.: Anatase Coarsening Kinetics under Hydrothermal Conditions as a Function of $\mathrm{pH}$ and Temperature. Chem. Mater. 20, 3443-3449 (2008)

8. Jolivet. J., Cassaignon, S., Chanéac, C., Chiche, D., Tronc, E.: Design of oxide nanoparticles by aqueous chemistry. J. Sol-Gel Sci. Technol. 46, 299-305 (2008)

9. Testino, A., Bellobono, I.R., Buscaglia, V., Canevali, C., D’Arienzo, M., Polizzi, S., Scotti, R., Morazzoni, F.: Optimizing the photocatalytic properties of hydrothermal $\mathrm{TiO}_{2}$ by the control of phase composition and particle morphology. A systematic approach. J. Am. Chem. Soc. 129, 3564-3575 (2007)

10. Reyes-Coronado, D., Rodríguez-Gattorno, G., Espinosa-Pesqueira, M.E., Cab, C., de Coss, R., Oskam, G.: Phase-pure $\mathrm{TiO}_{2}$ nanoparticles: anatase, brookite and rutile. Nanotechnology 19, 145605 (10pp.) (2008)

11. Sugimoto, T., Zhou, X., Muramatsu, A.: Synthesis of Uniform Anatase $\mathrm{TiO}_{2}$ Nanoparticles by Gel-Sol Method 1. Solution Chemistry of $\mathrm{Ti}(\mathrm{OH})_{\mathrm{n}}{ }^{(4-\mathrm{n})+}$ Complexes. J. Colloid Interface Sci. 252, 339-346 (2002) 
12. Pottier, A., Cassaignon, S., Chanéac, C., Villain, F., Tronc, E., Jolivet, J.: Size tailoring of $\mathrm{TiO} 2$ anatase nanoparticles in aqueous medium and synthesis of nanocomposites. Characterization by Raman spectroscopy. J. Mater. Chem. 13, 877-882 (2003)

13. Atashfaraz, M., Niassar, M.S., Ohara, S., Minami, K., Umetsu, M., Naka, T., Adschiri, T.: Effect of titanium dioxide solubility on the formation of BaTiO3 nanoparticles in supercritical water. Fluid Phase Equilib 257, 233237 (2007)

14. Schmidt, J., Vogelsberger, W.: Dissolution Kinetics of Titanium Dioxide Nanoparticles: The Observation of an Unusual Kinetic Size Effect. J. Phys. Chem. B 110, 3955-3963 (2006)

15. Vogelsberger, W., Schmidt, J., Roelofs, F.: Dissolution kinetics of oxidic nanoparticles: The observation of an unusual behaviour. Colloids Surf. A $324,51-57(2008)$

16. Roelofs, F., Vogelsberger, W.: Dissolution kinetics of nanodispersed $\gamma-$ alumina in aqueous solution at different $\mathrm{pH}$ : Unusual kinetic size effect and formation of a new phase. J. Colloid. Interface. Sci. 303, 450-459 (2006)

17. Ziemniak, S.E., Jones, M.E., Combs, K.E.S.: Solubility Behavior of Titanium(IV) Oxide in Alkaline Media at Elevated Temperatures. J Solution Chem. 22, 601-623 (1993)

18. Knauss, K.G., Dibley, M.J., Bourcier, W.L., Shaw, H.F.: Ti(IV) hydrolysis constants derived from rutile solubility measurements made from 100 to $300{ }^{\circ} \mathrm{C}$. Appl. Geochem. 16, 1115-1128 (2001)

19. Antignano, A., Manning, C.E.: Rutile solubility in $\mathrm{H}_{2} \mathrm{O}, \mathrm{H}_{2} \mathrm{O}-\mathrm{SiO}_{2}$, and $\mathrm{H}_{2} \mathrm{O}-\mathrm{NaAlSi}_{3} \mathrm{O}_{8}$ fluids at $0.7-2.0 \mathrm{GPa}$ and $700-1000{ }^{\circ} \mathrm{C}$ : Implications for mobility of nominally insoluble elements. Chem. Geol. 255, 283-293 (2008)

20. Audétat, A., Keppler, H.: Solubility of rutile in subduction zone fluids, as determined by experiments in the hydrothermal diamond anvil cell. Earth Planet. Sci. Lett. 232, 393-402 (2005)

21. Schuiling, R.D., Vink, B.W.: Stability relations of some titanium-minerals (sphene, perovskite, rutile, anatase). Geochim. Cosmochim. Acta 31, 2399-2411 (1967) 
22. Leturcq, G., Advocat, T., Hart, K., Berger, G., Lacombe, J., Bonnetier, A.: Solubility study of Ti,Zr-based ceramics designed to immobilize longlived radionuclides. Am. Mineral. 86, 871-880 (2001)

23. Liberti, A., Chiantella, V., Corigliano, F.: Mononuclear hydrolysis of titanium (IV) from partition equilibria. J. Inorg. Nucl. Chem. 25, 415-427 (1963)

24. Nabivanets, B.I., Lukachina, V.V.: Hydroxy complexes of titanium (IV). Ukrain. Khim. Zhur. 30, 1123-1128 (1964)

25. Kelsall. G.H., Robbins, D.J.: Thermodynamics of Ti- $\mathrm{H}_{2} \mathrm{O}-\mathrm{F}(-\mathrm{Fe})$ Systems at 298 K. J. Electroanal. Chem. 283, 135-157 (1990)

26. Comba, P., Merbach, A.: The Titanyl Question Revisited. Inorg. Chem. 26, 1315-1323 (1987)

27. Einaga, H.: Hydrolysis of Titanium(IV) in Aqueous $(\mathrm{Na}, \mathrm{H}) \mathrm{Cl}$ Solution. Dalton Trans. 12, 1917-1919 (1979)

28. Yokoi, K., van den Berg, C.M.G.: Determination of Titanium in Sea Water Using Catalytic Cathodic Stripping Voltammetry. Anal. Chim. Acta. 245, 167-176 (1991)

29. Schmidt, J.: Charakterisierung des Löseverhaltens oxidischer Nanopartikel $\left(\mathrm{TiO}_{2}, \mathrm{ZrO}_{2}, \mathrm{SiO}_{2}\right)$ in wässrigen Systemen. Thesis, Friedrich-SchillerUniversität Jena, Jena, Germany (2008)

30. Kraus, W., Nolze, G.: PowderCell for Windows Version 2.4. Bundesanstalt für Materialforschung und -prüfung, Berlin (2000)

31. Barringer, E.A., Bowen, H.K.: High-Purity, Monodisperse $\mathrm{TiO}_{2}$ Powders by Hydrolysis of Titanium Tetraethoxide. 1. Synthesis and Physical Properties. Langmuir 1, 414-420 (1985)

32. Löbbus, M., Vogelsberger, W., Sonnefeld, J., Seidel, A.: Current Considerations for the Dissolution Kinetics of Solid Oxides with Silica. Langmuir 14, 4386-4396 (1998)

33. Kosmulski, M.: The significance of the difference in the point of zero charge between rutile and anatase. Adv. Colloid Interface Sci. 99, 255-264 (2002)

34. Hiemstra, T., Venema, P., Van Riemsdijk, W.H.: Intrinsic Proton Affinity of Reactive Surface Groups of Metal (Hydr)oxides: The Bond Valence Principle. J. Colloid Interface Sci. 184, 680-692 (1996) 
35. Vogelsberger, W.: Thermodynamic and Kinetic Considerations of the Formation and the Dissolution of Nanoparticles of Substances Having Low Solubility. J. Phys. Chem. B 107, 9669-9676 (2003)

36. Lencka. M.M., Riman, R.E.: Thermodynamic Modeling of Hydrothermal Synthesis of Ceramic Powders. Chem. Mater. 5, 61-70 (1993)

37. Wolfram, S.: Das Mathematica-Buch. Addison Wesley Longman, Bonn, Germany (1997)

38. Grenthe, I., Wanner, H., Östhols, E.: TDB-2, Guidelines for the Extrapolation to Zero Ionic Strength. OECD Nuclear Energy Agency (2000) 